\title{
A Structural Equation Model of Leader-Member Exchange, Employee-Supervisor Relationship, Performance Appraisal, and Career Development
}

\author{
William Joseph Henkel \\ Park University and Southern New Hampshire University \\ Al C. Endres
Walden University
}

Some employees perceive that supervisors do not accurately reflect employees' performance or effectively differentiate among employees' performances during performance appraisals (PAs). Other employees believe the performance feedback they receive is not valuable for supporting their career development (CD). Leader-member exchange (LMX) and the distributive and interactional justice dimensions of organizational justice theories comprised the theoretical frameworks in this study for examining the significance of the relationships among LMX and employee-supervisor relationships (ESRs) and those relationships' potential influence on employees' CD through the PA process. Participants consisted of 44 defense contractor employees in the United States. Results from partial least squares analysis for the structural equation model indicated significant $(p<.01)$ positive relationships between LMX, ESR, PA, and CD. Furthermore, the results indicated that a positive relationship between LMX and ESR can influence employees' CD through the mediating effect of employees' perceptions of their PAs. The implications for positive social change include the potential to improve communications between employees and supervisors for benefiting employees' CD for improving employees' families' quality of life and employees' contributions to their communities.

Keywords: leader-member exchange (LMX), employee-supervisor relationship (ESR), performance appraisal (PA), career development (CD)

\section{Introduction}

Effective employee-supervisor relationships (ESRs) promote employees' trust in supervisors, employees' career development (CD), positive organizational relationships, and organizational effectiveness (Casimir, Ng, Wang, \& Ooi, 2014). Supervisors' effective use of the performance appraisal (PA) process is one pathway to positive ESR within organizations. However, some employees believe that although PAs are an annual requirement, that supervisors do not recognize the importance of PAs (Sumelius, Bjorkman, Ehrnrooth, Makela, \& Smale, 2014). Furthermore,

I wish to thank the Walden University faculty members who have provided me with instructions and guidance in acquiring the knowledge and skills that enabled me to complete my doctoral study. I would also like to acknowledge Dr. Sarah Prince and the Walden University Writing Staff for providing me with valuable guidance. Finally, I would like to express a special acknowledgment to my committee-Dr. Al Endres, my chairperson; Dr. Matthew Gonzalez, my second committee member; and Dr. Robert Hockin, the University Research Reviewer-for their guidance and feedback throughout my doctoral journey. 
Dusterhoff, Cunningham, and MacGregor (2014) concluded that some managers and researchers believe that PAs are of little or no importance because of the interpersonal relationships involved. Also, some employees consider PAs to be valueless because they believe their supervisors focus on completing PAs rather than ensuring the accuracy of the evaluations (Sumelius et al., 2014).

Supervisors can promote positive interaction and trust with employees through using effective communication to affect high-level LMX and ESR and, through the PA process, assist employees with CD (Casimir et al., 2014). However, the 2015 Federal Employee Viewpoint Survey results indicated that federal employees believe that their supervisors do not understand the relationship between LMX and ESR on employees' CD through the PA process (U.S. Office of Personnel Management, 2015).

\section{Purpose Statement}

The purpose of this quantitative correlation study was to examine the extent and nature of the influence of the relationship between LMX and ESR on defense contractors' employees' CD through the mediating effect of employees' perceived efficacy of the PA process. Findings from this study could motivate supervisors to increase positive LMX and ESR to facilitate employees' CD and increase organizational performance by increasing employee satisfaction and performance. Supervisors could also improve PA processes to enhance employees' technical and leadership skills to accelerate employees' CD.

\section{Research Question}

The structural equation model (SEM) in Figure 1 reflects the principal research question: To what extent does the relationship between LMX and ESR influence employees' CD through the mediating effect of employees' perceived efficacy of the PA process? As portrayed in Figure 1, the model reflects a direct pathway between (a) the independent exogenous formative variable LMX and ESR, (b) the independent variables LMX and ESR and the dependent endogenous reflective variable PA, and (c) the dependent variable PA and the dependent endogenous reflective variable CD. Furthermore, as depicted in Figure 1 and discussed throughout the article, the model reflects the estimated path coefficients (for $p<.05$ ) and the estimated coefficients of determination $\left(R^{2}\right)$ for PA and CD.

\section{Hypotheses}

Hypothesis 10: There is no significant relationship between LMX and ESR.

Hypothesis 1a: There is a significant relationship between LMX and ESR.

Hypothesis 20: There is no significant relationship between LMX and ESR that influences employees' perceived efficacy of the PA process.

Hypothesis 2a: There is a significant relationship between LMX and ESR that influences employees' perceived efficacy of the PA process.

Hypothesis 30: There is no significant relationship between LMX and ESR that influences employees' CD through the mediating effect of employees' perceived efficacy of the PA process.

Hypothesis 3a: There is a significant relationship between LMX and ESR that influences employees' CD through the mediating effect of employees' perceived efficacy of the PA process. 


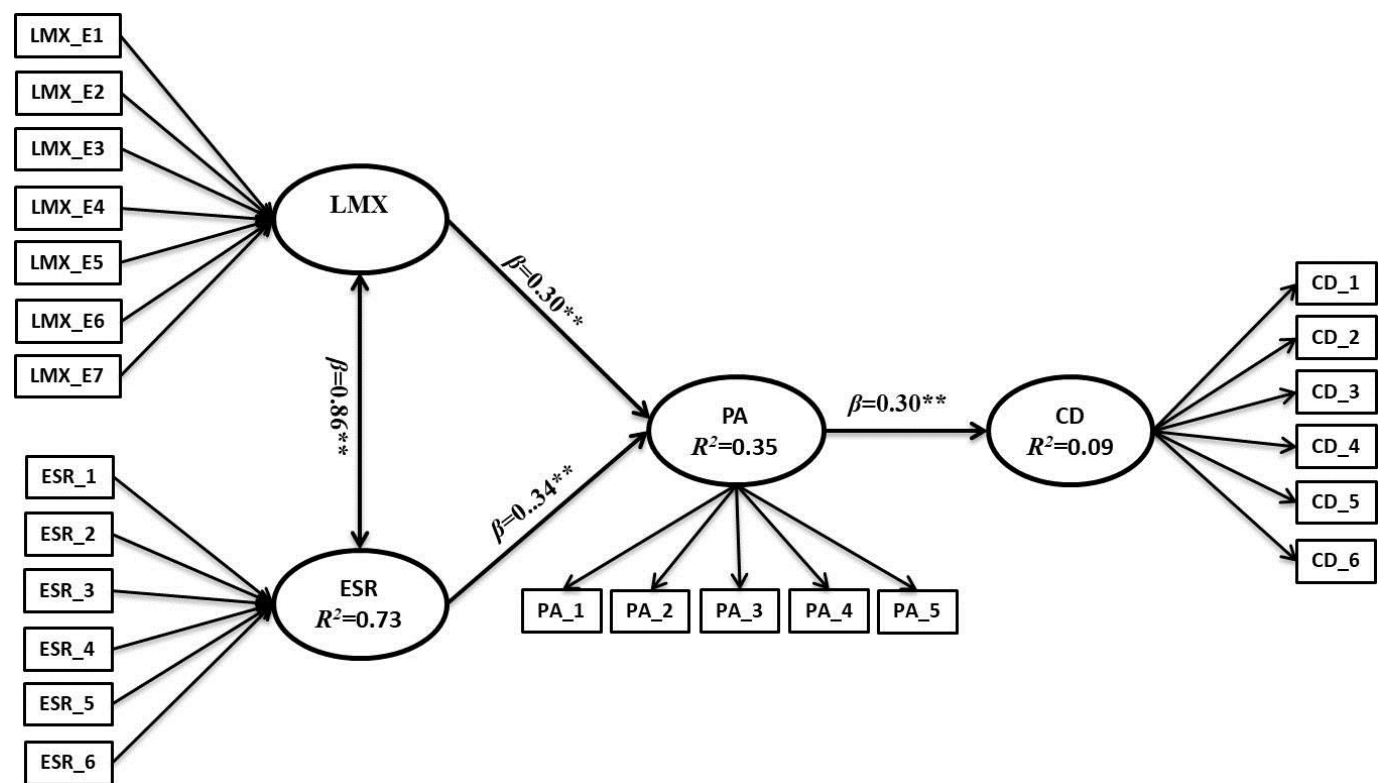

Figure 1. A structural equation model of leader-member exchange (LMX), employee-supervisor relationship (ESR), performance appraisal (PA), and career development (CD).

$* p<.05 .{ }^{* *} p<.01 .{ }^{* * *} p<.001$.

\section{Operational Definitions}

The following definitions are for the key terms in the study.

Career development (CD): $\mathrm{CD}$ is the integration of employees' career planning with the organization's career management program for developing employees' long-term career within the organization (Lo, Lin, Tung-Hsing, \& Tu, 2014).

Employee-supervisor relationship (ESR): ESR is the relationship that supervisors develop with their employees to promote (a) employees' trust in supervisors, (b) employees' CD, (c) positive organizational relationships, and (d) organizational effectiveness (Casimir et al., 2014).

Identification issues: Hair, Ringle, and Sarstedt (2011) used this term to explain the limitations of using covariance-based SEM to identify either prediction objectives or causal effects of latent variables.

Leader-member exchange (LMX): LMX is the measure of employees' perceptions of their relationships with their supervisors as articulated through (a) trust, (b) respect, (c) competence, (d) commitment, and (e) professionalism (Graen \& Uhl-Bien, 1995).

Performance appraisal (PA): Researchers defined PA as the process that supervisors use to mentor and develop employees to increase employees' value as an organizational asset and create value for the organization (Tsai, Tsai, \& Chang, 2013; Wei, 2015). 


\section{A Review of the Professional and Academic Literature}

Managers encourage supervisors to develop positive working relationships with their employees through LMX (Casimir et al., 2014). Positive interactions between employees and supervisors develop ESR through increasing employees' trust in supervisors, enhancing employees' CD, promoting positive organizational relationships, and enhancing organizational effectiveness (Casimir et al., 2014).

\section{Leader-Member Exchange}

Researchers have identified trust, respect, obligation, competence, and commitment as key LMX dimensions (Dulebohn, Bommer, Liden, Brouer, \& Ferris, 2012; Graen \& Uhl-Bien, 1995). Dysvik, Buch, and Kuvaas (2015) noted that trust between employees and supervisors is the basis for high levels of social and economic LMX and, therefore, is paramount for knowledge sharing between employees and supervisors. Furthermore, employees who share high LMX with their supervisors develop high ESR through trust and respect. High-LMX enhances high ESR through trust and selfefficacy, thereby influencing employees' service performances, increasing trust, encouraging ethical behavior, increasing mutual respect, and developing high ESR (Fein, Tziner, Lusky, \& Palachy, 2013; Tandon \& Ahmen, 2015).

Researchers noted that supervisors base their relationships with their employees on the employees' competence and commitment (Dulebohn et al., 2012). Furthermore, supervisors use competence as a measure when conducting PAs and allocating training resources to enhance employees' CD.

Dulebohn et al. also noted that high LMX and supervisors' support increases employees' competence. Furthermore, Fisk and Friesen (2012) postulated that high-level LMX and ESR between employees and supervisors increased employees' perceptions of supervisors' commitment and competence, thereby increasing employees' job satisfaction.

\section{Employee-Supervisor Relationship}

There are six ESR dimensions (communications, fairness, feedback, civility, justice and equity, and honesty) that influence employees' perceptions of their supervisors' character during the execution of organizational procedures (Moorman, 1991). Moorman claimed that to develop trust and fairness in the relationship, supervisors should communicate effectively with their employees. They should not only stress the importance of fairness to their employees but also exhibit fairness in their behavior. Byrne, Pitts, Wilson, \& Steiner (2012) noted that employees' perceptions of supervisors' interpersonal and informational justice (fairness) during the PA process increased their trust in supervisors. Furthermore, Byrne et al. identified that the two dimensions of interactional justice (interpersonal and informational) are drivers of employees' trust in their supervisors.

Moorman (1991) postulated that supervisors could promote a positive relationship with their employees by communicating effectively and providing employees with objective feedback. Gumusluoglu, Karakitapoglu-Aygun, and Hirst (2013) noted that supervisors who treat employees as individuals by providing feedback with dignity, respect, kindness, honesty, and genuine concern for employees' opinions can increase the levels of LMX and ESR.

Kong (2013) observed that supervisors who are supportive and civil can influence employees' perceptions of their work environment and increase ESR. Also, Moorman (1991) concluded that supervisors promote ESR by showing concern for employees' rights by demonstrating justice and equality in the relationship. Furthermore, Kacmar, Carlson, and Harris (2013) concluded that there 
is an increase in high ESR when employees perceive that their supervisors exhibit high ethical and honest leadership traits.

\section{Performance Appraisal}

Waldman (1997) identified five dimensions of employees' perceptions of their organization's PA program: assessment accuracy, rating fairness, performance improvement, CD, and satisfaction in their organization's PA system. Krats and Brown's (2013) findings indicated that PA accuracy partially mediates employees' job satisfaction and organizational commitment, and organizational leadership should periodically evaluate their organization's PA process to ensure that employees are receiving fair and accurate appraisals. In addition, Sumelius et al. (2014) postulated that employees' perceptions of PA fairness affect employees' organizational commitment and that numerous stimuli affect employees' perceptions of their organizations' PA processes, such as job satisfaction, organizational commitment, turnover intentions, and trust in supervisors.

Harrington and Lee (2015) noted the positive relationships between employees' perceptions of PA fairness and LMX. Raemdonck and Strijbos (2013) proposed that if employees perceived that their supervisors' PA ratings were fair and their supervisors' feedback focused on the specificity of their performances, areas for improvement, and CD, employees would have a positive view of their supervisors' ratings and feedback. Karkoulian, Assaker, and Hallak (2016) postulated that supervisors' goals for conducting employees' PAs should provide employees with feedback to increase their performance and organizational commitment to facilitate the accomplishment of organizational goals. Also, Waldman (1997) stated that effective supervisors use PAs not only to gather information on employees' performance but also to evaluate employees' CD goals. Lopes, Sarraguca, Lopes, and Duarte (2015) noted that employees' perceptions of supervisors' trust during the PA process increased employees' perceptions of the fairness and efficacy of their organizations' PA systems. Furthermore, Culberston, Henning, and Payne (2013) believed that positive feedback, during the PA process, should lead to employees' satisfaction with the PA results, and positive PA feedback is positively related to PA satisfaction.

\section{Career Development}

Employees' level of organizational commitment increases once the employees believe that their leadership is genuinely concerned about their career advancement (Bravo, Seibert, Kraimer, Wayne, \& Liden, 2015). Also, Kraimer, Seibert, Wayne, Liden, and Bravo (2011) suggested that when employees experience high levels of organizational support for professional development, employees' organizational commitment increases. Furthermore, Bednall, Sanders, and Runhaar (2014) concluded that both employees and the organization benefit from leaders' CD planning.

Kraimer et al. (2011) stressed that employees participating in organizational training, positive LMX and professional mentoring are more likely to perceive that their organizational leaders support employees' CD opportunities. Furthermore, Kim, Kang, Lee, and McLean (2016) noted that employees who experienced high CD opportunities in their organization also possessed high organizational commitment. Kraimer et al. concluded that employees who perceived that their organizational leaders supported CD were more likely to achieve individual goals. Correspondingly, Dill, Morgan, and Weiner (2014) postulated that when supervisors support employees' CD, employees' perceptions of career goal achievement are higher and their job satisfaction is higher. Furthermore, Seibert, Kraimer, Holtom, and Pierotti (2013) determined that career goals, career planning, and career satisfaction influenced employees to further their education. 


\section{Methodology}

The quantitative methodology and a cross-sectional correlational design were the means for examining the extent and nature of the relationship among LMX, ESR, PA, and CD via SEM. Using SEM enabled determining all relational pathways within the model simultaneously (Lowry \& Gaskin, 2014). The decision to use partial least squares structural equation modeling (PLS-SEM) resulted from the need to examine the significance and nature of the relationship between the independent variables (LMX and ESR) and the dependent variables (PA and CD). Furthermore, using PLS-SEM minimizes residual variance, is more robust with fewer identification issues, works well with small and large samples, and incorporates multidimensional (formative and reflective) constructs (Hair et al., 2011). Previous researchers have described PLS-SEM as a "soft" modeling technique that lessens demands on measurement scales, sample sizes, and residual distributions (Henseler \& Sarstedt, 2013).

\section{Population and Sampling}

The population for this study comprised employees from seven defense contractor companies employed at military installations in the United States. The survey samples consist of 44 validated surveys from 100 distributed surveys. Samples from employees reflected participants who had received PAs within the past year.

Researchers have noted that PLS-SEM is robust and works well with small sample sizes and that there is no preferred standard sample size calculator to estimate minimum sample sizes for PLSSEM (Hair, Hult, Ringle, \& Sarstedt, 2014; Kock \& Hadaya, 2018). The chosen sample size analysis used researchers' (Adachi \& Willoughby, 2015; Field, 2014; Fritz, Cox, \& MacKinnon, 2015; Sham \& Purcell, 2014) recommendations for employing a statistical power level of .80, an anticipated effect size of .15, and a probability alpha value of .01 for the model's four latent variables and 24 observed variables.

Because the study included three sets of research questions and null hypotheses, Cohen's (1992) guidelines provided the justification for using $\alpha=.01$ for studies testing multiple null hypotheses. Therefore, employing Cohen's recommendation to use a minimum expected $R^{2}$ value of .50, from Exhibit 1.7: Minimum $R^{2}$ Calculation Table in Hair et al.'s (2014) book, we calculated the minimum sample size using both $\alpha$ s of .01 and .05 . Our result for the sample size calculation results using a minimum $R^{2}$ value of .50 and an $\alpha$ of .01 was 47 samples, and the result for an $\alpha$ of .05 was 33 samples. In further support of the adequacy of the survey's response rate of 44 participants, the a priori minimum sample size estimated from Kock and Hadaya's (2018) inverse square root formula for the average path coefficient size of the four estimated path coefficient results (.43) was 34 samples. Furthermore, the results of using Kock's (2017) recommended WarpPLS 5.0 data analysis yielded $p<.01$ for each structural path in the model.

\section{Data Collection Instruments}

The business problem was examined through using four survey instruments to determine if (and how) the relationship between LMX and ESR could influence employees' perceived efficacy of the PA for guiding employees' CD. The four survey instruments employed for measuring the relationships between LMX, ESR, PA, and CD were (a) Graen and Uhl-Bien's (1995) seven-item LMX instrument, (b) Moorman's (1991) six-item Interactional Justice instrument, (c) Waldman's (1997) five-item Appraisal System Satisfaction instrument, and (d) Kraimer et al.'s (2011) six-item Perceived Career Opportunity instrument. Confidence in the instruments' applicability for the current study's 
population was justified from the internal consistency reliability estimates for Cronbach's a and composite reliability $(\rho c)$ coefficients $>.90$, thereby demonstrating internal consistency reliability (Hair et al., 2014; Sarstedt, Ringle, Smith, Reams, \& Hair, 2014).

Graen and Uhl-Bien (1995) validated their seven-item LMX instrument through a series of studies. Graen and Schiemann's (1978) result of Cronbach's $\alpha=.91$ indicated a strong internal consistency reliability value. Moorman's (1991) result of Cronbach's $\alpha=.93$ for the Interactional Justice Scale indicated strong internal consistency reliability. Waldman's (1997) result of Cronbach's $\alpha=.81$ for his first study and $\alpha=.82$ for his second study using the Appraisal System Satisfaction measure indicated acceptable internal consistency reliability. Kraimer et al.'s (2011) result of Cronbach's $\alpha=$ .91 indicated strong internal consistency reliability for their Perceived Career Opportunity instrument.

\section{Data Collection and Analysis Technique}

Participants provided their responses to each of the instruments' items based on an ordinal Likerttype 5-point scale ranging from 1 (disagree strongly) to 5 (agree strongly). Participants' responses were obtained from the SurveyMonkey website and analyzed using IBM's SPSS 23 software package and Koch's (2017) WarpPLS 5.0 software package. In alignment with Hair et al.'s (2014), Kock's (2015), and Sarstedt et al.'s (2014) requirements for composite reliability coefficients ( $\rho c>.60)$ and Cronbach's alphas $(\alpha>.70)$, the current study's results indicated that the study's instruments were sufficiently reliable for the study's population. Field (2014) noted that researchers reported that a Cronbach's alpha value (split-half reliability) between .70 and .80 was an acceptable measure of the internal consistency reliability of a scale, and a Cronbach's alpha value above .90 was a strong internal consistency reliability value (p. 709). The analysis revealed that the Cronbach's alphas for instruments in the current study were all $>.90$ and the composite reliabilities were also all $>.90$, thereby demonstrating internal consistency reliability.

\section{Presentation of the Findings}

The response data frequencies indicated that the majority of the respondents replied that their relationships with their supervisors were better than average, with $25 \%$ indicating that their relationships with their supervisors were extremely effective, which indicated that they share highquality exchanges with their supervisor. However, $5 \%$ of the respondents consistently replied with a low rating indicating low-quality exchanges, thereby supporting Dulebohn et al.'s (2012) identification of LMX dichotomies (low-quality exchange and high-quality exchange). Reviewing the response data also indicated that $70 \%$ of respondents reported that their PAs were both fair and accurate assessments of their performance. However, $5 \%$ of the respondents consistently replied with low ratings with over $30 \%$ indicating that their organizations' PA systems did not help them with their CD. Therefore, the overall results indicated that although there were high-quality LMX and ESR within the organizations, a distinct minority of the employees perceived that organizational leaders did not use the PA system to develop employees and thereby increase employees' CD opportunities.

\section{Measurement Model Assessment Results}

As recommended by Kock (2015), the WarpPLS 5.0 software also enabled generating 100 bootstrapped samples from the original dataset. The Mode $\mathrm{M}$ function within the PLS software facilitated examining the potential influence that the indicator variables have on the latent variables by identifying the indicator variables as being either formative or reflective. 
Reviewing the findings in Table 1 revealed that the $p$ values for the average path coefficient (.450) and the average $R^{2}$ (.392) were both significant at the .001 level. Estimating the degree of fit of the model also stemmed from using Koch's (2015) WarpPLS 5.0 software. Using Kock's criteria, the results of the analysis indicated that the fit indices criteria supported the model's fit to the data and the model's possessing adequate predictive and explanatory qualities. Furthermore, following Hair et al.'s (2014), Kock's (2015), and Sarstedt et al.'s (2014) recommendations, because the analysis resulted in an average variance inflation factor (2.009), which is lower than the critical value of 3.3, there was no statistically significant evidence of collinearity among the latent variables.

Table 1. Model Fit Indices and p Values ( $\mathrm{N}=44)$

\begin{tabular}{lcc}
\hline Analysis & Results & Remarks \\
\hline Average path coefficient & 0.450 & $p<.001$ \\
Average $R^{2}$ & 0.392 & $p<.001$ \\
Average adjusted $R^{2}$ & 0.372 & $p<.001$ \\
Average block VIF & 2.009 & acceptable if $\leq 5$, ideally $\leq 3.3$ \\
Average full collinearity VIF & 2.811 & acceptable if $\leq 5$, ideally $\leq 3.3$ \\
Algorithm used in analysis & NA & Warp3, PLS Mode A multiple regression \\
Resampling method used in the analysis & NA & Bootstrapping \\
Number of data resamples used & 100 & \\
Number of iterations to obtain estimates & 6 & \\
Only ranked data used in analysis & Yes & \\
\hline
\end{tabular}

Note. VIF = variance inflation factor; NA = not applicable. Adapted from Karakoc and Ozer (2016).

In addition to developing and reviewing the model fit indexes in Table 1, a confirmatory factor analysis to test the fit of data to the model demonstrated Hair et al.'s (2014), Kock's (2015), and Sarstedt et al.'s (2014) criterion that the minimum outer loading value $>.70$ convergent validity was met. The analyses results also indicated that the combined loadings were $>.70$, except for two indicator variables with values $<.70(.618, .603)$, and the $p$ values were $<.01$. Furthermore, following Hair et al.'s, Kock's, and Sarstedt et al.'s guidance, the results indicated discriminant validity because all indicator variables' loadings on their associated latent variables were larger than the indicator variables' loadings on adjacent latent variables.

Examining the indicator variables' assessment results revealed that the indicator variables' weights were nonsignificant $(p>.05)$ except for indicator variable PA $1(p=.050)$. However, because the indicator variable assessment results indicated that the variables' combined loadings were $>.50$, per Hair et al.'s (2014), Kock's (2015), and Sarstedt et al.'s (2014) guidance, the indicator variables are important to the structural model. Therefore, because the formative indicator variables' combined loadings were $>.50$, and following Hair et al.'s, Kock's, and Sarstedt et al.'s guidance, it was justified to retain the formative indicator variables. Furthermore, discriminant validity was demonstrated because the reflective indicator variables' combined loadings were $<.70$, and the indicator variables loaded higher on their latent variable than on adjacent latent variables within the path model. Therefore, following Hair et al.'s, Kock's, and Sarstedt et al.'s guidance, retaining all of the model's reflective indicator variables was justified.

Hair et al.'s (2014) and Wong's (2013) recommendations for assessing a model's predictive accuracy of $R^{2}$ values as being (a) substantial predictive accuracy $\left(R^{2}>.75\right)$, (b) moderate predictive accuracy $\left(.25<R^{2}<.75\right)$, and (c) weak predictive accuracy $\left(R^{2}<.25\right)$ were employed. The results of the analysis for the $R^{2}$ values indicate substantial predictive accuracy for the exogenous latent variable ESR $\left(R^{2}=.734\right)$ and the endogenous latent variable PA $\left(R^{2}=.349\right)$ and weak predictive accuracy for the endogenous latent variable CD $\left(R^{2}=.092\right)$. 
Following Hair et al.'s (2014), Kock's (2015), and Sarstedt et al.'s (2014) guidance, the PLS-SEM results indicate that the model has convergent validity. Furthermore, following Hair et al.'s, Kock's, and Sarstedt et al.'s guidance, because the reflective latent variables (PA, CD) do not share variance with another reflective latent variable, the results indicated that the SEM model has discriminant validity.

The SEM analysis also provided the basis for examining the relationships among LMX, ESR, PA, and CD. As shown in Figure 1, the results indicate that there are significant and positive relationships among the pairs of latent variables: (a) LMX and $\operatorname{ESR}(\beta=.86, p<.01)$, (b) LMX and PA $(\beta=.30, p=.01)$, (c) ESR and PA $(\beta=.34, p=.01)$, and (d) PA and CD $(\beta=.30, p=.01)$. Furthermore, the results indicate that LMX explained (a) $73 \%$ of the variance in ESR, (b) LMX and ESR explained $35 \%$ of the variance in PA, and (c) PA explained $9 \%$ of the variance in CD.

Kock's (2017) Warp3 PLS program also provided the basis for calculating the absolute effect size value of the PLS path model between the two exogenous latent variables (LMX, ESR) and the endogenous latent variable (PA). Following Hair et al.'s (2014), Kock's (2015), and Wong's (2013) guidance, the absolute effect size values indicate a large effect size (>.35) for LMX to ESR (effect size $=.734 ; \beta=.86)$. The absolute effect size values also indicate medium effect sizes for LMX to PA (effect size $=.162 ; \beta=.30$ ) and ESR to PA (effect size $=.187 ; \beta=.34$ ), and small effect size for PA to $\mathrm{CD}$ (effect size $=.092 ; \beta=.30$ ). Following the same authors' guidance, the absolute effect size value indicated a small effect size $(>.02$ but $<.15)$ for the PA to CD (absolute effect size $=.092 ; \beta=.14$ ). Correspondingly, $\mathrm{Q}^{2}$ measures the effect size of predictor exogenous latent variables on endogenous latent variables (Hair et al., 2014; Kock, 2015; \& Wong, 2013). Therefore, per the authors' guidance that values greater than 0 have predictive relevance, the results of the $\mathrm{Q} 2$ analysis indicated that both endogenous latent variables' reflective indicators, PA $(\mathrm{Q} 2=.358)$ and $\mathrm{CD}(\mathrm{Q} 2=.101)$, have predictive relevance to the structural model.

\section{Addressing the Research Questions Through Hypotheses Testing}

\section{Subsidiary Research Question 1. To What Extent Does a Relationship Exist Between LMX and ESR?}

The statistical significance of the path coefficient between LMX and ESR (as illustrated in Figure 1) indicated a significant positive relationship between LMX and ESR $(\beta=.86, p<.01)$. Therefore, because the relationship between LMX and ESR is significant and positive, the analysis results justified rejecting Hypothesis $1_{0}$, and support accepting the Hypothesis $1_{\mathrm{a}}$ : There is a significant relationship between LMX and ESR.

\section{Subsidiary Research Question 2. To What Extent Does the Relationship Between LMX and ESR} Influence the Employees' Perceived Efficacy of the PA Process?

The statistical significance of the path coefficient between (a) LMX and ESR, (b) LMX and PA, and (c) ESR and PA (as illustrated in Figure 1) indicated a significant positive relationship between (a) LMX and ESR ( $\beta=.86, p<.01)$, (b) LMX and PA $(\beta=.30, p=.01)$, and (c) ESR and PA $(\beta=.34, p<$ .01). Therefore, because the relationships between LMX and ESR, LMX and PA, and ESR and PA were significant and positive, the results support rejecting Hypothesis 20 , and support accepting Hypothesis 2a: There is a significant relationship between LMX and ESR that influences employees' perceived efficacy of the PA process. Furthermore, the path coefficient results provide evidence that there is a significant positive relationship between LMX and ESR, LMX and PA, and ESR and PA, thereby supporting that the relationship between LMX and ESR can influence the employees' perceptions of the efficacy of their organization's PA process. 


\section{Subsidiary Research Question 3. Does the Relationship Between LMX and ESR Significantly Influence Employees' CD Through the Mediating Effect of Employees' Perceived Efficacy of the} PA Process?

Estimating the indirect effect of the mediating variable PA between the independent latent variable LMX and the dependent latent variable CD, and between the independent latent variable ESR and the dependent latent variable CD (Figure 2) provided the means for testing the Hypothesis $3_{0}$.

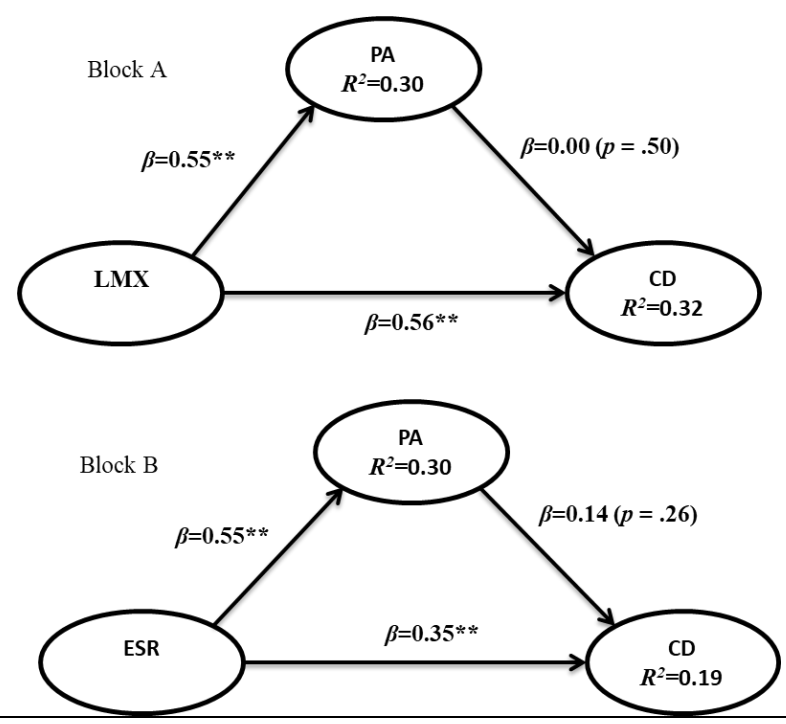

Figure 2. Mediator Variable (Performance Appraisal [PA]) Indirect Effect. $L M X=$ leader-member exchange; $C D=$ career development; $E S R=$ employee-supervisor relationship. $* p<.05$. ** $p<.01 . * * * p<.001$.

Kock's (2014) process and decision criteria were the means for determining the significance of the indirect effect of a mediating variable on the path coefficient of an independent variable and a dependent variable. Kock's (2017) WarpPLS 5.0 software provided the estimates of the indirect effects and the associated $p$ values. Kock's (2014) first criterion for the significance of the (PA) mediating variable was that there must be a significant path coefficient $(p<.05)$ between the independent variables (in this study, LMX and ESR in Figure 2) and the dependent variable (in this study, CD in Figure 2, Blocks A and B) was met. Furthermore, Kock's second criterion for the mediating effect of being significant was there must also be significant path coefficients $(p<.05)$ between the independent variables (LMX, ESR) and the mediating variable (PA; Figure 2, Blocks A and $\mathrm{B})$ was met. Therefore, the significant path coefficients in Block A between LMX and CD $(\beta=$ $.56, p<.01)$, and LMX and PA $(\beta=.55, p<.01)$, and in Block B between ESR and CD $(\beta=.35, p<$ $.01)$, and ESR and PA $(\beta=.55, p<.01)$ satisfied Kock's criterion for the significance of the mediating effect of PA.

For full mediation to exist in either Block A or Block B, there must be at least one nonsignificant path coefficient between PA and CD (Kock, 2014). Because as shown in Figure 2, there are nonsignificant path coefficients in Block A between PA and CD $(\beta=.00, p=.50)$, and in Block B between PA and CD $(\beta=.14, p=.26)$, there is a full mediation effect of the variable PA on the path coefficients between LMX and CD, and ESR and CD. Subsequently, the results of analyzing the indirect effects supported Hypothesis 3a: There is a significant relationship between LMX and ESR 
that influences employees' CD through the mediating effect of employees' perceived efficacy of the PA process. Furthermore, the analysis of the path coefficients provided evidence that there is a significant positive relationship between LMX and ESR, LMX and PA, and ESR and PA. Finally, the analysis of the indirect effects analysis of mediation provides evidence that LMX and ESR can indirectly influence CD through the mediating effects of employees' perceptions of the efficacy of their organizations' PA process.

\section{Discussion}

\section{Applications to Professional Practice}

The findings of this study provide evidence of a significant positive relationship between LMX and ESR. Therefore, the potential application to professional business practice is demonstrating the importance of managing employees' perceived levels of their relationship with their supervisor. The findings also indicate that the relationship between LMX and ESR can influence employees' CD through the mediating effect of employees' perceived efficacy of their organizations' PA process. Furthermore, the findings support the potential application to professional business practice by demonstrating to managers and supervisors that the relationship between LMX and ESR can influence employees' CD through the mediating effect of employees' perceived efficacy of the PA process.

\section{Implications for Social Change}

The findings provide evidence that positive LMX and ESR can cultivate supervisors' positive internal corporate social responsibilities (CSRs) toward their employees. Managers who encourage high-level LMX can also increase high-level ESR within their organizations, and therefore, catalyze CSRs and positive social changes (Mason \& Simmons, 2014). Furthermore, managers who incorporate CSRs into HR policies, such as recognizing employees' social responsibilities during the PA process, create positive human capital for increasing organizational value and achieving competitive advantage (Mason \& Simmons, 2014; Shen \& Benson, 2016).

\section{Conclusion}

Organizational competitive advantage is difficult to achieve and maintain within the global economy. Business competition continues to grow with organizations spending time and money to attract and retain high-quality employees. The findings, conclusions, and recommendations from the study provide supervisors and managers with potential catalysts for recognizing, developing, and retaining skilled professional employees. The results of this study can also provide employees with the knowledge and evidence that they can be key contributors to organizations, and through an effective PA process, can receive guidance for effecting CD from their supervisors for benefiting their families and communities.

\section{References}

Adachi, P., \& Willoughby, T. (2015). Interpreting effect sizes when controlling for stability effects in longitudinal autoregressive models: Implications for psychological science. European Journal of Developmental Psychology, 12, 116-128. doi:10.1080/17405629.2014.963549

Bednall, T. C., Sanders, K., \& Runhaar, P. (2014). Stimulating informal learning activities through perceptions of performance appraisal quality and human resource management system 
strength: A two-wave study. Academy of Management Learning and Education, 13, 45-61. doi:10.5465/amle.2012.0162

Bravo, J., Seibert, S. E., Kraimer, M. L., Wayne, S. J., \& Liden, R. C. (2015). Measuring career orientations in the era of the boundaryless career. Journal of Career Assessment, 25, 502525. doi:10.1177/1069072715616107

Byrne, Z. S., Pitts, V. E., Wilson, C. M., \& Steiner, Z. J. (2012). Trusting the fair supervisor: The role of supervisory support in performance appraisals. Human Resource Management Journal, 22, 129-147. doi:10.1111/j.1748-8583.2012.00193.x

Casimir, G., Ng, Y. N., Wang, Y. K., \& Ooi, G. (2014). The relationships amongst leader-member exchange, perceived organizational support, affective commitment, and in-role performance: A social-exchange perspective. Leadership \& Organization Development Journal, 35, 366385. doi:10.1108/LODJ-04-2012-0054

Cohen, J. (1992). A power primer. Psychological Bulletin, 112, 155-159. doi:10.1037/00332909.112.1.155

Culberston, S. S., Henning, J. B., \& Payne, S. C. (2013). Performance appraisal satisfaction: The role of feedback and goal orientation. Journal of Personnel Psychology, 12, 189-195. doi:10.1027/1866-5888/a000096

Dill, J. S., Morgan, J. C., \& Weiner, B. (2014). Frontline health care workers and perceived career mobility: Do high-performance work practices make a difference. Health Care Manage Review, 39, 318-328. doi:10.1097/HMR.0b013e31829fcbfd

Dulebohn, J. H., Bommer, W. H., Liden, R. C., Brouer, R. L., \& Ferris, G. R. (2012). A meta-analysis of antecedents and consequences of leader-member exchange: Integrating the past with an eye toward the future. Journal of Management, 38, 1715-1759.

doi:10.1177/0149206311415280

Dusterhoff, C., Cunningham, J. B., \& MacGregor, J. N. (2014). The effects of performance rating, leader-member exchange, perceived utility, and organizational justice on performance appraisal satisfaction: Applying a moral judgment perspective. Journal of Business Ethics, 119, 265-273. doi:10.1007/s10551-013-1634-1

Dysvik, A., Buch, R., \& Kuvaas, B. (2015). Knowledge donating and knowledge collecting: The moderating roles of social and economic LMX. Leadership \& Organization Development Journal, 36, 35-53. doi:10.1108/LODJ-11-2012-0145

Fein, E. C., Tziner, A., Lusky, L., \& Palachy, O. (2013). Relationships between ethical climate, justice perceptions, and LMX. Leadership \& Organization Development Journal, 34, 147-163. doi:10.1108/01437731311321913

Field, A. (2014). Discovering statistics using IBM SPSS Statistics. New Delhi, India: SAGE Publications India Pvt Ltd.

Fisk, G. M., \& Friesen, J. P. (2012). Perceptions of leader emotion regulation and LMX as predictors of followers' job satisfaction and organizational citizenship behaviors. The Leadership Quarterly, 1, 1-12. doi:10.1016/j.leaqua.2011.11.001

Fritz, M. S., Cox, M. G., \& MacKinnon, D. P. (2015). Increasing statistical power in mediation models without increasing sample size. Evaluation \& the Health Professions, 38, 343-366. doi:10.1177/0163278713514250

Graen, G. B., \& Schiemann, W. (1978). Leader-member agreement: A vertical dyad linkage approach. Journal of Applied Psychology, 63, 206-212. doi:10.1037/0021-9010.63.2.206 
Graen, G. B., \& Uhl-Bien, M. (1995). Relationship-based approach to leadership: Development of leader-member exchange (LMX) theory of leadership over 25 years: Applying a multi-level multi-domain perspective. The Leadership Quarterly, 6, 219-247. doi:10.1016/10489843(95)90036-5

Gumusluoglu, L., Karakitapoglu-Aygun, Z., \& Hirst, G. (2013). Transformational leadership and R\&D workers' multiple commitments: Do justice and span of control matter? Journal of Business Research, 66, 2269-2278. doi:10.1016/j.jbusres.2012.02.039

Hair, J. F., Hult, G. T., Ringle, C. M., \& Sarstedt, M. (2014). A primer on partial least squares structural equation modeling (PLS-SEM). Los Angeles, CA: Sage.

Hair, J. F., Ringle, C. M., \& Sarstedt, M. (2011). PLS-SEM: Indeed a silver bullet. Journal of Marketing Theory and Practice, 19, 139-151. doi:10.2753/MTP1069-6679190202

Harrington, J. R., \& Lee, J. H. (2015). What drives perceived fairness of performance appraisal? Exploring the effects of psychological contract fulfillment on employees' perceived fairness of performance appraisal in U.S. federal agencies. Public Personnel Management, 44, 214-238. doi:10.1177/0091026014564071

Henseler, J., \& Sarstedt, M. (2013). Goodness-of-fit indices for partial least squares path modeling. Computational Statistics, 28, 565-580. doi:10.1007/s00180-012-0317-1

Kacmar, K. M., Carlson, D. S., \& Harris, K. J. (2013). Interactive effect of leaders' influence tactics and ethical leadership on work effort and helping behavior. The Journal of Social Psychology, 153, 577-597. doi:10.1080/00224545.2013.798248

Karakoc, E. Y., \& Ozer, G. (2016). The budget-related antecedents of job performance. International Journal of Research in Business \& Social Science, 5, 38-53. doi:10.20525/ijrbs.v5i3.165

Karkoulian, S., Assaker, G., \& Hallak, R. (2016). An empirical study of 360-degree feedback, organizational justice, and firm sustainability. Journal of Business Research, 69, 1862-1867. doi:10.1016/j.jbusres.2015.10.070

Kim, H., Kang, D.-s., Lee, S.-w., \& McLean, G. (2016). Career commitment as a mediator between organization-related variables and motivation for training and turnover intentions. Journal of Career Development, 43, 130-144. doi:10.1177/0894845315584160

Kock, N. (2014). Advanced mediating effects tests, multi-group analyses, and measurement model assessments in PLS-based SEM. International Journal of e-Collaboration, 10, 1-13. doi:10.4018/ijec.2014010101

Kock, N. (2015). WarpPLS 5.0 user manual. Retrieved http://cits.tamiu.edu/WarpPLS/UserManual_v_5_0.pdf

Kock, N. (2015). WarpPLS: 5.0 [Computer software]. Retrieved from http://www.scriptwarp.com/warppls/

Kock, N., \& Hadaya, P. (2018). Minimum sample size estimation in PLS-SEM: The inverse square root and gamma-exponential methods. Information Systems Journal, 28, 227-261. doi:10.1111/isj.12131

Kong, H. (2013). Relationships among work-family supportive supervisors, career competencies, and job involvement. International Journal of Hospitality Management, 33, 304-309. doi:10.1016/j.ijhm.2012.09.006 
Kraimer, M. L., Seibert, S. E., Wayne, S. J., Liden, R. C., \& Bravo, J. (2011). Antecedents and outcomes of organizational support for development: The critical role of career opportunities. Journal of Applied Psychology, 96, 485-500. doi:10.1037/a0021452

Krats, P., \& Brown, T. C. (2013). Unionised employee's reactions to the introduction of a goal-based performance appraisal system. Human Resource Management Journal, 23, 396-412. doi:10.1111/j.1748-8583.2012.00205.x

Lo, H.-J., Lin, C.-H., Tung-Hsing, L., \& Tu, P.-F. (2014). The mediator effect of career development between personality traits and organizational commitment: The example of sport communication technology talents. The Turkish Online Journal of Educational Technology, 13, 137-143.

Lopes, S. A., Sarraguca, J. M., Lopes, J. A., \& Duarte, M. E. (2015). A new approach to talent management in law firms: Integrating performance appraisal and assessment center data. International Journal of Productivity and Performance Management, 64, 523-543. doi:10.1108/IJPPM-08-2013-0147

Lowry, P. B., \& Gaskin, J. (2014). Partial least squares (PLS) structural equation modeling (SEM) for building and testing behavioral causal theory: When to choose it and how to use it. IEEE Transactions on Professional Communication, 57, 123-146. doi:10.1109/TPC.2014.2312452

Mason, C., \& Simmons, J. (2014). Embedding corporate social responsibility in corporate governance: A stakeholder systems approach. Journal of Business Ethics, 119, 77-86. doi:10.1007/s10551012-1615-9

Moorman, R. H. (1991). Relationship between organizational justice and organizational citizenship behaviors: Do fairness perceptions influence employee citizenship? Journal of Applied Psychology, 76, 845-855. doi:10.1037/0021-9010.76.6.845

Raemdonck, I., \& Strijbos, J.-W. (2013). Feedback perceptions and attribution by secretarial employees: Effects of feedback-content and sender characteristics. European Journal of Training and Development, 37, 24-48. doi:10.1108/03090591311293275

Sarstedt, M., Ringle, C. M., Smith, D., Reams, R., \& Hair Jr., J. F. (2014). Partial least squares structural equation modeling (PLS-SEM): A useful tool for family business researchers. Journal of Family Business Strategy, 5, 105-115. doi:10.1016/j.jfbs.2014.01.002

Seibert, S. E., Kraimer, M. L., Holtom, B. C., \& Pierotti, A. J. (2013). Even the best laid plans sometimes go askew: Career self-management processes, career shocks, and the decision to pursue graduate education. Journal of Applied Psychology, 98, 169-182. doi:10.1037/a0030882

Sham, P. C., \& Purcell, S. M. (2014). Statistical power and significance testing in large-scale genetic studies. Nature Review Genetics, 15, 335-341. doi:10.1038/nrg3706

Shen, J., \& Benson, J. (2016). When CSR is a social norm: How socially responsible human resource management affects employee work behavior. Journal of Management, 42, 1723-1746. doi:10.1177/0149206314522300

Sumelius, J., Bjorkman, I., Ehrnrooth, M., Makela, K., \& Smale, A. (2014). What determines employee perceptions of HRM process features? The case of performance appraisal in MNC subsidiaries. Human Resource Management, 53, 569-592. doi:10.1002/hrm.21604

Tandon, M. S., \& Ahmen, O. (2015). Trust and self-efficacy: Interlink between LMX and service performance. The International Journal of Business \& Management, 3, 267-274. 
Tsai, M.-S., Tsai, M.-C., \& Chang, C.-C. (2013). The direct and indirect factors on affecting organizational sustainability. Journal of Management and Sustainability, 3, 67-77. doi:10.5539/jms.v3n4p67

U.S. Office of Personnel Management. (2015). Federal employee viewpoint survey results: Employees influencing change. Washington, DC: Author.

Waldman, D. A. (1997). Predictors of employee preferences for multirater and group-based performance appraisal. Group \& Organization Management, 22, 264-287. doi:10.1177/1059601197222007

Wei, Y.-C. (2015). Do employees high in general human capital tend to have higher turnover intention? The moderating role of high-performance HR practices and P-O fit. Personnel Review, 44, 739-756. doi:10.1108/PR-07-2013-0137

Wong, K. K.-K. (2013). Partial least squares structural equation modeling (PLS-SEM) techniques using SmartPLS. Marketing Bulletin, 24, 1-32.

The International Journal of Applied Management and Technology (IJAMT), sponsored by Walden University's School of Management, is a peer-reviewed, online journal that addresses contemporary national and international issues related to management and technology. The objectives of the IJAMT are to: (a) encourage collaborative and multi-disciplinary examinations of important issues in business and technology management, and (B) engage scholars and scholar-practitioners in a dynamic and important dialogue.

Walden University Publishing: http://www.publishing.waldenu.edu 